\title{
The Relationship between Leaf Rolling and Ascorbate-Glutathione Cycle Enzymes in Apoplastic and Symplastic Areas of Ctenanthe setosa Subjected to Drought Stress
}

\author{
NESLIHAN SARUHAN ${ }^{1, *}$, RABIYE TERZI ${ }^{2}$, AYKUT SAGLAM $^{2}$ \\ and ASIM KADIOGLU
}

\author{
${ }^{1}$ Department of Biology, Faculty of Arts and Sciences, Rize University, 53100, Rize, Turkey \\ ${ }^{2}$ Department of Biology, Faculty of Arts and Sciences, Karadeniz Technical University, 61080, Trabzon, \\ Turkey
}

\begin{abstract}
The ascorbate-glutathione (ASC-GSH) cycle has an important role in defensive processes against oxidative damage generated by drought stress. In this study, the changes that take place in apoplastic and symplastic ASC-GSH cycle enzymes of the leaf and petiole were investigated under drought stress causing leaf rolling in Ctenanthe setosa (Rosc.) Eichler (Marantaceae). Apoplastic and symplastic extractions of leaf and petiole were performed at different visual leaf rolling scores from 1 to 4 ( 1 is unrolled, 4 is tightly rolled and the others are intermediate forms). Glutathione reductase (GR), a key enzyme in the GSH regeneration cycle, and ascorbate (ASC) were present in apoplastic spaces of the leaf and petiole, whereas dehydroascorbate reductase (DHAR), which uses glutathione as reductant, monodehydroascorbate reductase (MDHAR), which uses NAD $(\mathrm{P}) \mathrm{H}$ as reductant, and glutathione were absent. GR, DHAR and MDHAR activities increased in the symplastic and apoplastic areas of the leaf. Apoplastic and symplastic ASC and dehydroascorbate (DHA), the oxidized form of ascorbate, rose at all scores except score 4 of symplastic ASC in the leaf. On the other hand, while reduced glutathione (GSH) content was enhanced, oxidized glutathione (GSSG) content decreased in the leaf during rolling. As for the petiole, GR activity increased in the apoplastic area but decreased in the symplastic area. DHAR and MDHAR activities increased throughout all scores, but decreased to the score 1 level at score 4. The ASC content of the apoplast increased during leaf rolling. Conversely, symplastic ASC content increased at score 2 , however decreased at the later scores. While the apoplastic DHA content declined, symplastic DHA rose at score 2, but later was down to the level of score 1. While GSH content enhanced during leaf rolling, GSSG content did not change except at score 2. As well, there were good correlations between leaf rolling and ASC-GSH cycle enzyme activities in the leaf (GR and DHAR) and leaf rolling and GSSG. These results showed that in apoplastic and symplastic areas, ASC-GSH cycle enzymes leading ROS detoxification may have a role in controlling leaf rolling.
\end{abstract}

Key terms: Ctenanthe setosa, antioxidant enzymes, antioxidant substances, drought, leaf rolling.

\section{ABBREVIATIONS}

$\mathrm{ASC}=$

$\mathrm{APX}=$

$\mathrm{AWF}=$

$\mathrm{DHA}=$

$\mathrm{DHAR}=$

DTNB =

$\mathrm{GSH}=$ ascorbate;

ascorbate peroxidase; apoplastic washing fluid;

dehydroascorbate;

dehydroascorbate reductase;

5,5'-dithiobis-(2-nitrobenzoic acid); reduced glutathione;

$\begin{array}{ll}\text { GSSG }= & \text { oxidized glutathione; } \\ \text { G6PDH }= & \begin{array}{l}\text { glucose- } 6 \text {-phosphate dehydrogenase; } \\ \text { glutathione reductase; }\end{array} \\ \text { GR }= & \text { high-performance liquid chromatography; } \\ \text { HPLC }= & \text { monodehydroascorbate reductase; } \\ \text { POD }= & \text { peroxidase; } \\ \text { ROS }= & \text { reactive oxygen species; } \\ \text { RWC }= & \text { relative water content; } \\ \text { SOD }= & \text { superoxide dismutase; } \\ g_{s}= & \text { stomatal conductance }\end{array}$

GSSG $=$ oxidized glutathione

glucose-6-phosphate dehydrogenase

HPLC $=$ high-performance liquid chromatography;

MDHAR $=$ monodehydroascorbate reductase

relative water content;

$g_{s}=\quad$ stomatal conductance

\footnotetext{
* Corresponding author: Address: Department of Biology, Faculty of Arts and Sciences, Rize University, 53100, RizeTurkey, E-mail: neslihansaruhan@hotmail.com, Tel: 9046422361 26, Fax: 904642235376
} 


\section{INTRODUCTION}

Leaf rolling is one of the most frequent responses to drought stress in some plants (Begg, 1980). Leaf rolling reduces effective leaf area and transpiration, and therefore is a potentially useful drought avoidance mechanism in arid areas (Clarke, 1986). Rolling also increases drought resistance in cereal crops (Townley-Smith and Hurd, 1979).

When plants are subjected to environmental stresses, some reactive oxygen species (ROS) such as superoxide $\left(\mathrm{O}_{2}^{-\cdot}\right)$, hydrogen peroxide $\left(\mathrm{H}_{2} \mathrm{O}_{2}\right)$, hydroxyl radicals $\left({ }^{\circ} \mathrm{OH}\right)$ and singlet oxygen $\left({ }^{1} \mathrm{O}_{2}\right)$ are produced (Li and Staden, 1998). Removal of ROS is strictly controlled by an array of non-enzymatic and enzymatic antioxidant mechanisms in plants. Ascorbate (ASC) and glutathione $(\mathrm{GSH})$ are the key nonenyzmatic antioxidants and play important roles in protecting cellular components from oxidative stress (Smirnoff and Pallanca, 1996). Both compounds are involved in maintaining cellular redox status. Moreover, both react directly and neutralize ${ }^{1} \mathrm{O}_{2}$ and $\cdot \mathrm{OH}$ (Dalton, 1995). Ascorbate is involved in several physiological processes in plant cell compartments, particularly in the apoplast. Ascorbate is also a substrate for cell wall peroxidases and plays a role in the regulation of cell wall lignification (Takahama and Oniki, 1992; De Cabo et al., 1996; Mehlhorn et al., 1996).

Enzymatic ROS scavenging includes superoxide dismutase (SOD, EC 1.15.1.1), which dismutates $\mathrm{O}_{2}{ }^{\cdot-}$ to $\mathrm{H}_{2} \mathrm{O}_{2}$. Subsequently, the ascorbate peroxidase (APX, EC 1.11.1.11) destroys the $\mathrm{H}_{2} \mathrm{O}_{2}$. However in plant cells, components of the ASC-GSH cycle, which is comprised of ASC, GSH, APX, monodehydroascorbate reductase (MDHAR, EC 1.6.5.4), dehydroascorbate reductase (DHAR, EC 1.8.5.1), and glutathione reductase (GR, EC 1.6.4.2), are more effective in $\mathrm{H}_{2} \mathrm{O}_{2}$ detoxification mechanism (Asada, 1999; Möller, 2001; del-Rio et al., 2002). Once used by APX, ASC is oxidized to the monodehydroascorbate radical that is reduced to ASC by MDHAR or disproportionately to ASC and dehydroascorbate (DHA). Dehydroascorbate undergoes irreversible hydrolysis to 2,3-diketogulonic acid or is reduced to $\mathrm{ASC}$, which is a reaction catalyzed by dehydroascorbate reductase (DHAR). Glutathione also participates in the regeneration of ASC from DHA by enzyme DHAR. In this reaction, glutathione is oxidized to glutathione disulphide (GSSG). Glutathione acts as disulphide reductant to protect thiol groups on enzymes and is regenerated by GR in a NADPH dependent reaction (Arora et al., 2002). Glutathione plays a protective role in scavenging of single oxygen, peroxides and hydroxyl radicals and is involved in recycling of reduced ASC in the ASC-GSH pathway in chloroplasts (Foyer, 1993).

The apoplast, including the cell wall, has been defined as the extraprotoplastic matrix of plant cells. The apoplast is involved in many physiological processes of the cell, for instance nutrition, growth, and defense. Also, the apoplast matrix contains many enzymatic and non-enzymatic components (Dietz, 1997). Abiotic stresses, such as high salinity (Hernandez et al., 2001), ozone treatment (Jaspers et al., 2005) and water deficit $(\mathrm{Hu}$ et al., 2005) lead to rapid changes in the concentration and/or redox status of non-enzymatic components. Likewise, the effects of varied stress factors on the antioxidant systems of the apoplastic space have been studied by some authors, and results show that this area is important in the plant cell response to biotic stresses (Dietz, 1997; Vanacker et al., 1998; Lyons et al., 2001). However, little is known about the role of apoplastic antioxidant systems in defense against drought stress during leaf rolling in plants.

Ctenanthe setosa, a member of the family of tropical herbaceous perennials, is cultivated as a greenhouse ornamental plant and evidently shows a leaf rolling response to drought stress (Turgut and Kadioglu, 1998). It is a suitable plant model to explain the mechanism of leaf rolling because its leaves show gradual rolling over a long period (30-40 days). Thus, observation and following of leaf rolling are easy (Kadioglu and Terzi, 2007). As is known, C. setosa 
has a rhizome and a long petiole in the upper side of the soil. Moreover, the leaf shows rolling while the petiole has not yet made such a morphologically obvious adaptive response to drought. For this reason, we studied the antioxidant system in two parts of this plant; the lamina (without petiole, called 'leaf' or 'leaves' in this text) and the petiole.

In a previous study, we determined superoxide and $\mathrm{H}_{2} \mathrm{O}_{2}$ levels during leaf rolling and, suggested the roles of CAT, guaiacol peroxidase (GPX), APX and SOD in antioxidant defense mechanisms in apoplastic and symplastic areas of C. setosa under drought stress. In the present study, in order to determine the relationship between leaf rolling and enzymes of the ASC-GSH cycle under drought stress, we hypothesize that ASC-GSH cycle enzymes may have a role in controlling leaf rolling. However, there is no available information about antioxidant enzymes of ASC-GSH cycle during leaf rolling in plants. Our second hypothesis is that there are differences between the actions of antioxidant systems of the leaf and petiole because the leaf shows rolling, while the petiole does not show such a morphologically obvious adaptive response to drought. Therefore, this study focused on the changes in activities of ASC-GSH cycle enzymes (DHAR, MDHAR and GR), and antioxidant substances (ASC, DHA, GSH and GSSG) in apoplastic/symplastic areas of the lamina and petiole during leaf rolling in $C$. setosa subjected drought stress.

\section{MATERIAL AND METHODS}

Growth of the plants and stress applications

Ctenanthe setosa (Rosc.) Eichler (Marantaceae) plants were vegetatively propagated and grown in plastic pots (14 $\mathrm{cm}$ high, $16 \mathrm{~cm}$ top and $11 \mathrm{~cm}$ bottom diameter) containing peat and sand (5: 1). Plants of the same age were selected. The old and wilted leaves were trimmed. Plants were kept adequately watered and then incubated in a growth chamber with the following parameters: $16 \mathrm{~h}$ light and $8 \mathrm{~h}$ darkness at $25{ }^{\circ} \mathrm{C}$, relative humidity $70 \%$, photon flux density at the surface of the leaves $300 \mu \mathrm{mol} \mathrm{m} \mathrm{m}^{-2} \mathrm{~s}^{-1}$. Some plants were well-watered (control) throughout the experiment, while others were subjected to drought stress to achieve different visual leaf rolling scores from 1 to 4 (一 : $1, \cup$ : 2 , ( : $: 3, \bigcirc: 4)$ by withholding water for 56 days. Score 1 indicates no rolling (control plants), while score 4 indicates complete rolling. Visual leaf rolling scores were also used in other studies (e.g. O'Toole and Moya, 1978). The following parameters were measured in apoplastic and symplastic spaces during leaf rolling.

\section{Extraction of apoplastic washing fluid}

For antioxidant enzyme analysis, apoplastic washing fluid (AWF) was extracted by the vacuum infiltration method by Hernandez et al. (2001). Fresh leaf and petiole (2 g) were cut into $1 \mathrm{~cm}$ lengths, and rinsed in tap water six times to remove cellular proteins from the cut ends. Then, the leaf and petiole were vacuum-infiltrated for 20 min in $50 \mathrm{mM}$ potassium-phosphate buffer ( $\mathrm{pH}$ 6.5), containing $0.2 \mathrm{M} \mathrm{KCl}, 0.1 \mathrm{mM}$ $\mathrm{CaCl}_{2}$. The leaf and petiole were blotted dry and placed vertically in a $20 \mathrm{ml}$ syringe. The syringes were placed in centrifuge tubes. Apoplastic extract was collected from the bottom of the tubes after leaves and petioles were centrifuged at $1450 \mathrm{~g}$ and $825 \mathrm{~g}$ for $15 \mathrm{~min}$.

For glutathione and ascorbate, AWF was obtained from leaf and petiole by vacuum infiltration with $10 \mathrm{mM} \mathrm{KCl}$ solution $(\mathrm{pH}$ 6.8), modifying the method described by Takahama and Oniki (1992).

\section{Leaf enzyme extraction}

Following collection of AWF, the residual leaf material $(0.5 \mathrm{~g})$ was homogenized with $1 \%$ polyvinylpolypyrrolidone (PVPP) in 5 $\mathrm{ml}$ extraction buffer $(50 \mathrm{mM}$ potassiumphosphate buffer, $1 \mathrm{mM}$ EDTA $\mathrm{pH}$ 7.0). The symplastic homogenate was centrifuged at $18.000 \mathrm{~g}$ for $20 \mathrm{~min}$ at $4{ }^{\circ} \mathrm{C}$. Residual leaf extracts were decanted into eppendorf tubes for subsequent analysis. 
Glucose-6-phosphate dehydrogenase activity

Glucose-6-phosphate dehydrogenase (G6PDH EC 1.1.1.49) activity was used to assess the degree of cytoplasmic contamination of AWF. Activity was measured by following the reduction of NADP at $340 \mathrm{~nm}$ (Kornberg and Horecker, 1955) using $66 \mathrm{mM} \mathrm{K}_{2} \mathrm{HPO}_{4}(\mathrm{pH} \mathrm{7.6),} 10$ $\mathrm{mM} \mathrm{MgCl} 2,300 \mu \mathrm{M}$ NADP, 2 mM glucose6-phosphate and $50 \mu \mathrm{l}$ of extract. The activity of G6PDH was calculated using an extinction coefficient of $6.22 \mathrm{mM}^{-1} \mathrm{~cm}^{-1}$ for $\mathrm{NADPH}$ at $340 \mathrm{~nm}$.

\section{Antioxidant enzyme analysis}

Glutathione reductase activity was determined following the decrease in absorbance at $340 \mathrm{~nm}$ associated with the oxidation of NADPH (Foyer and Halliwell, 1976). The assay contained $50 \mathrm{mM}$ Tris$\mathrm{HCl}(\mathrm{pH} 7.8), 150 \mu \mathrm{M}$ NADPH, $500 \mu \mathrm{M}$ oxidised glutathione (GSSG) and $50 \mu \mathrm{l}$ extract.

Monodehydroascorbate reductase activity was determined by following the oxidation of NADH at $340 \mathrm{~nm}$ (Hossain et al., 1984). The assay contained $50 \mathrm{mM}$ $\mathrm{K}_{2} \mathrm{HPO}_{4}(\mathrm{pH} 7.8), 150 \mu \mathrm{M}$ NADH, $500 \mu \mathrm{M}$ ASC, $0.4 \mathrm{U}$ ascorbate oxidase and $50 \mu \mathrm{l}$ of extract. Rates obtained in the absence of ascorbate oxidase were subtracted. The activity of MDHAR was calculated using an extinction coefficient of $6.22 \mathrm{mM}^{-1} \mathrm{~cm}^{-1}$ for NADH at $340 \mathrm{~nm}$.

Dehydroascorbate reductase activity was assayed essentially, as described before (Hossain and Asada, 1984). The leaf and petiole samples were ground in extraction buffer (50 mM Tris-HCl, pH 7.4, $100 \mathrm{mM}$ $\mathrm{NaCl}, 2 \mathrm{mM}$ EDTA and $1 \mathrm{mM} \mathrm{MgCl}_{2}$ ) and centrifuged at $18.000 \mathrm{~g}$ for $20 \mathrm{~min}$ at $4^{\circ} \mathrm{C}$. The assay contained $50 \mathrm{mM} \mathrm{K} \mathrm{HPO}_{4} /$ $\mathrm{KH}_{2} \mathrm{PO}_{4}, \mathrm{pH} 6.5,0.5 \mathrm{mM}$ DHA and $1 \mathrm{mM}$ $\mathrm{GSH}$ and its activity was determined from the increase in absorbance at $265 \mathrm{~nm}$ following the production of ASC. DHAR activity was calculated using an extinction coefficient of $14 \mathrm{mM}^{-1} \mathrm{~cm}^{-1}$ for ASC at 265 $\mathrm{nm}$.

\section{Antioxidant analysis}

Antioxidants were analyzed immediately after AWF extraction. To extract ASC and $\mathrm{GSH}$, fresh leaf and petiole $(0.5 \mathrm{~g})$ were ground in $5 \mathrm{ml}$ of $5 \%$ metaphosphoric acid containing $1 \mathrm{mM}$ EDTA. The homogenate was centrifuged at $10.000 \mathrm{~g}$ for $5 \mathrm{~min}$ at 4 ${ }^{\circ} \mathrm{C}$. Residual leaf extracts were decanted into eppendorf tubes for subsequent analysis.

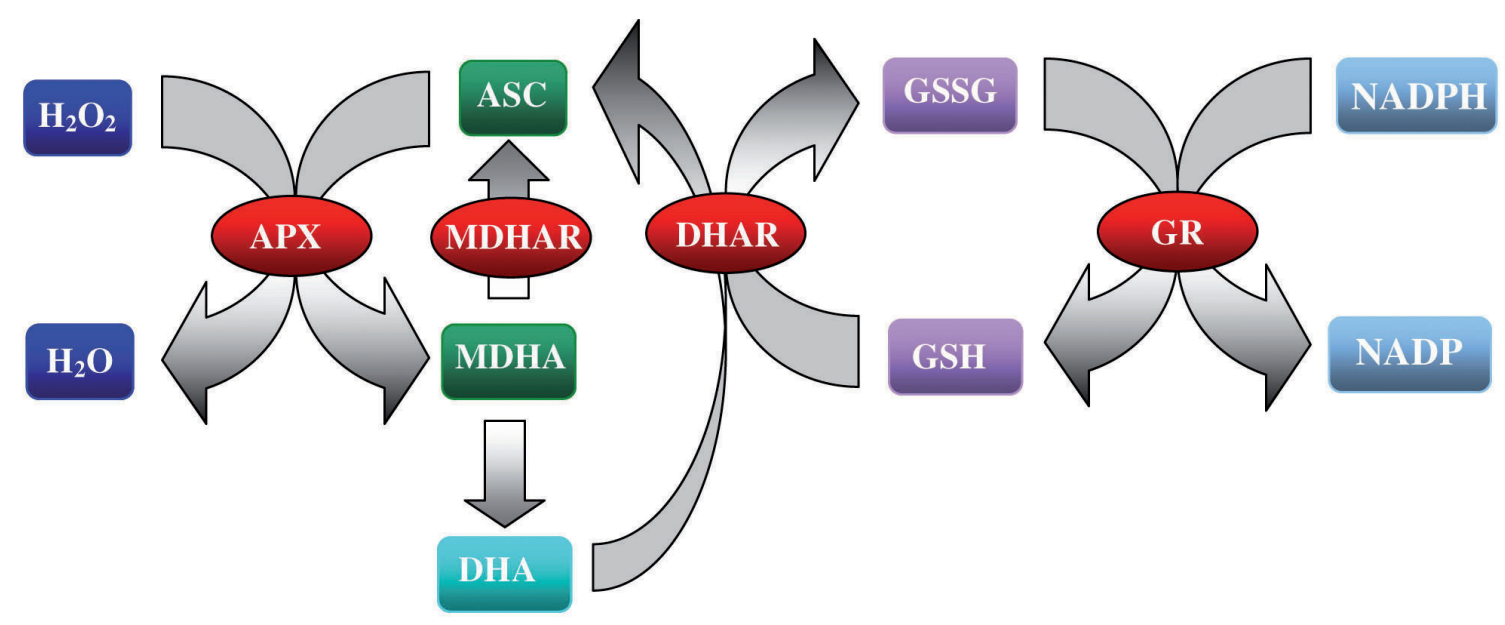

Figure 1: Ascorbate-Glutathione Cycle. ASC: Ascorbate; APX: Ascorbate peroxidase; GSH: Reduced glutathione; GSSG: Oxidized glutathione; GR: Glutathione reductase; DHA; Dehydroascorbate; DHAR: Dehydroascorbate reductase; MDHA: Monodehydroascorbate; MDHAR: Monodehyroascorbate reductase. 
Glutathione content was determined by the spectrophotometric method of Griffith (1980), using an assay based on the enzymatic recycling of GSH, where GSH was sequentially oxidized and reduced by 5,5'-dithiobis-(2-nitrobenzoic acid) (DTNB) and GR, respectively, The rate of formation DTNB was monitored at $412 \mathrm{~nm}$. Glutathione (as GSH+GSSG) was measured using an assay mixture containing $250 \mathrm{mM}$ $\mathrm{K}_{2} \mathrm{HPO}_{4} / \mathrm{KH}_{2} \mathrm{PO}_{4} \quad(\mathrm{pH} \quad 7.5), 200 \mu \mathrm{M}$ NADPH, $600 \mu \mathrm{M}$ DTNB, $25 \mu$ l extract and $0.3 \mathrm{U}$ GR. The change in absorbance at 412 $\mathrm{nm}$ was recorded for $3 \mathrm{~min}$. The extract was incubated to determinate the content of GSSG alone with 2-vinylpyridine for $1.5 \mathrm{~h}$ at $25{ }^{\circ} \mathrm{C}$. Glutathione concentrations were calculated from a standard curve constructed using GSH over the range 0-5 $\mu \mathrm{M}$.

For symplastic ASC content, two grams of fresh leaves and petioles were homogenized in 5\% $\mathrm{m}$-phosphoric acid. The homogenates were centrifuged at $4.500 \mathrm{~g}$ for $15 \mathrm{~min}$ at $4{ }^{\circ} \mathrm{C}$. The supernatants were collected and lyophilized. The lyophilizates were dissolved in the same extraction solvent, centrifuged at $9.000 \mathrm{~g}$ for $10 \mathrm{~min}$ at $4{ }^{\circ} \mathrm{C}$, filtered $(0.45 \mu \mathrm{m}$ Milipore filter $)$ and directly injected $(10 \mathrm{ml})$ to HPLC. For apoplastic and symplastic ASC contents, the high-performance liquid chromatographic (HPLC) system has been used in the present study consisted of an Agilent 1100 Series (Palo Alto, CA) equipped with a quaternary HPLC pump, micro vacuum degasser, thermostated column compartment, UV/VIS detector, standard micro and preparative autosampler. Ascorbate and dehydroascorbate analysis were performed on Ace 5 C18 (ACE, Scotland) column (25 $\mathrm{cm} \times 4.6 \mathrm{~mm}$ i.d., $10 \mathrm{~mm}$ particle size) operating at $25{ }^{\circ} \mathrm{C}$ with flow rate $2 \mathrm{ml} / \mathrm{min}$. Elution was affected using a linear gradient of the solvent mixture $0.02 \mathrm{M}$ potassium phosphate ( $\mathrm{pH} 2.04)$. The automatic injection system had a $10 \mathrm{ml}$ sample loop. Detection was done by a HP 1100 Series multivariable wavelength detector at a wavelength of $210 \mathrm{~nm}$. Acid components were identified by comparison of their retention times to those of authentic standards under the above analysis conditions. Standard solutions of dehydroascorbic acid and ascorbic acid (each containing $25 \mathrm{mg} / \mathrm{ml}$ in mobile phase) were injected into the column. With those two standard solutions, calibration curves for each of the acids were made,

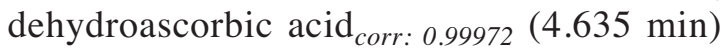
and ascorbic acid corr: $0.99992(7.611 \mathrm{~min})$, which were later used for assessing the concentrations corresponding to the different peaks in the chromatograms. The areas of peaks of compounds were quantified by the HP ChemStations software.

\section{Statistical analysis}

All analyses were repeated three times with three replicates. Variance of mean values was performed with the Duncan Multiple Comparison Test using SPSS software for Microsoft Windows (Ver. 10.0, SPSS Inc., USA) and significance level was determined at the $5 \%(\mathrm{P}<0.05)$ level.

\section{RESULTS}

\section{Apoplastic antioxidant enzymes}

G6PDH activity as a cytoplasmic marker enzyme was measured to determine the cytoplasmic contamination of each apoplastic sample. Our results showed that AWF was free from symplastic contamination. G6PDH activity in AWF was below the limits of detection $(1 \%)$ in C. setosa. It was found $0.075 \%, 0.070 \%$, $0.061 \%, 0.086 \%$ in the leaf and $0.19 \%$, $0.15 \%, 0.32 \%, 0.47 \%$ in the petiole at score $1,2,3$ and 4 , respectively.

GR activity, one of the ASC-GSH cycle enzymes was shown in Fig. 2A. GR was present in AWF of the leaf and petiole, but DHAR and MDHAR were not. GR activity increased during the rolling period in the leaf. A significant positive correlation between leaf rolling and GR activity ( $\mathrm{r}$ $=0.92$ ) was observed during the rolling period (Table 3 ). In the petiole, GR activity increased up to score 3 , but then decreased. The activity in apoplast 
increased by $19.5 \%, 93 \%$ and $285 \%$ in the leaf and $26 \%, 46 \%$ and $5.5 \%$ in the petiole at score 2, 3 and 4 , respectively.

\section{Antioxidant enzymes of residual leaf and petiole}

GR, DHAR and MDHAR were present in the symplastic space of the leaf and petiole. Symplastic GR activity did not change at score 2, but increased by $79 \%$ and $93 \%$ at score 3 and 4 compared to score 1 in the leaf. In the petiole, symplastic GR activity decreased $31 \%, 14 \%$ and $19.5 \%$ at score 2, 3 and 4 compared to score 1 , respectively (Fig. 2B). In addition, there was a significant correlation between leaf rolling and GR activity ( $\mathrm{r}=0.91)$ in the leaf (Table 3 ).
Activities of ASC-recycling enzymes (DHAR and MDHAR) also showed changes at different visual leaf rolling scores during the drought period. The activity of DHAR in the leaf significantly increased during the rolling. The activity of DHAR in the leaf was higher than that of the petiole. The activity increased by $101 \%, 172 \%$ and 193 $\%$ in the leaf at score 2, 3 and 4, respectively. In the petiole, the activity statistically rose up to score 3 , but decreased to the level of score 1 at score 4. The activity increased by $40 \%, 43 \%$ and $13 \%$ in the petiole at score 2,3 and 4 , respectively (Fig. 3). These changes were associated with an increase in GSH content. In addition, a very significant $(\mathrm{P}<0.01)$ positive correlation between leaf rolling
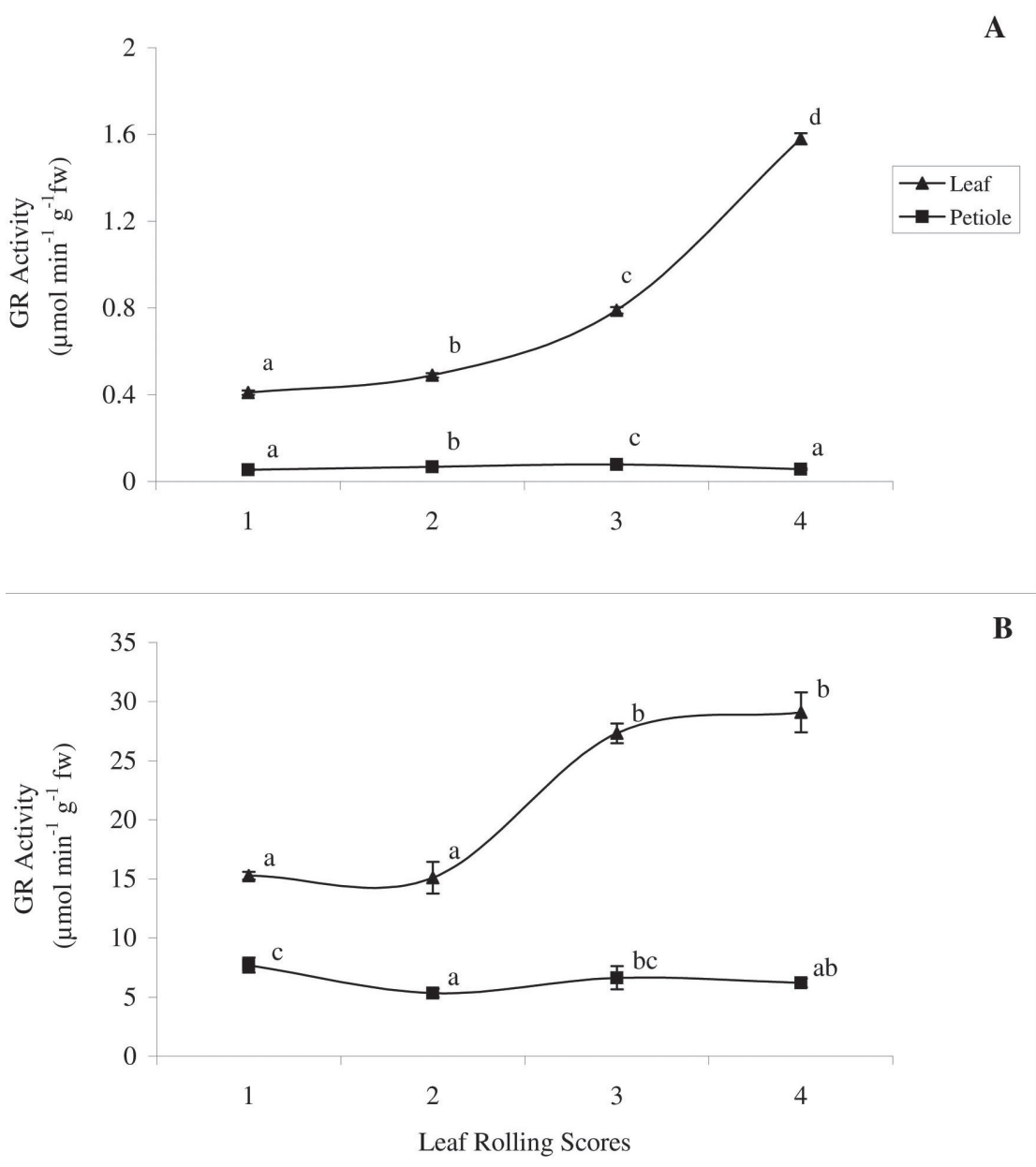

Figure 2: GR activity in the apoplast (A) and symplast (B) of leaves and petioles. The vertical bars represent standard deviation of the means of three replicates. Leaf or leaves were used for lamina (without petiole). ( $\mathbf{\Delta})$ Leaf; ( $\mathbf{\square})$ Petiole. 
and DHAR activity $(\mathrm{r}=0.96)$ was observed during the rolling period (Table 3 ).

MDHAR activities in the leaf and petiole increased during leaf rolling. In the leaf and petiole, the activities at score 2 and 3 were found statistically important, but not at score 4 in the petiole. The activity increased by 88 $\%, 128 \%$ and $83.5 \%$ in the leaf and $67 \%$, $105 \%$ and $8 \%$ in the petiole at score 2, 3 and 4 compared to score 1, respectively (Fig.
4). There were no good correlations between the rolling and MDHAR activities in the leaf and petiole (Table 3 ).

\section{Apoplastic antioxidants}

Because both ASC and GSH are potent scavengers of ROS, it is of interest to determine whether ASC and GSH contents change in apoplatic and symplastic areas

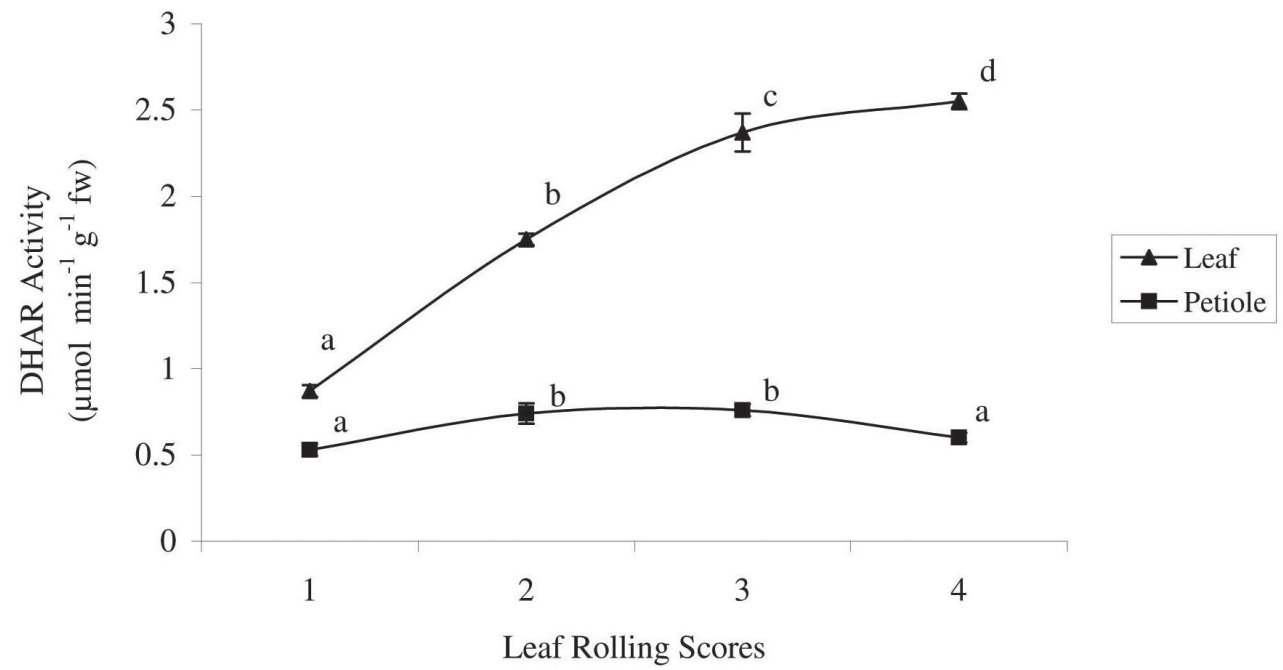

Figure 3: DHAR activity in the symplast of leaves and petioles. The vertical bars represent standard deviation of the means of three replicates. Leaf or leaves were used for lamina (without petiole). ( $\mathbf{\Delta})$ Leaf; (ם) Petiole.

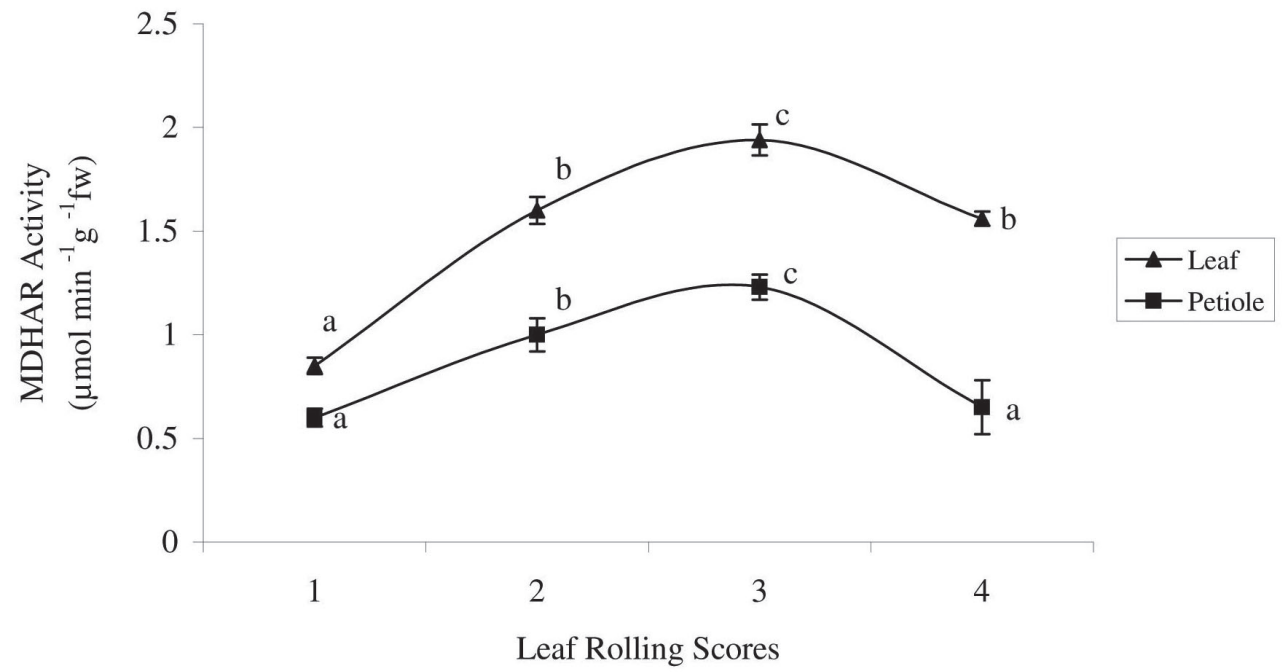

Figure 4: MDHAR activity in the symplast of leaves and petioles. The vertical bars represent standard deviation of the means of three replicates. Leaf or leaves were used for lamina (without petiole). ( $\boldsymbol{\Delta}$ ) Leaf; ( $\boldsymbol{\square})$ Petiole. 
during leaf rolling. It was found that apoplastic washing fluid does not contain GSH and GSSG. However, the ASC content of the apoplast increased at all scores compared to score 1 in the leaf and petiole. The increases were significant at all scores in the leaf and petiole. The same tendency was observed for the changes in DHA content. The apoplastic DHA content was observed to accumulate at all scores in the leaf, but declined in the petiole (Table 1). However, we did not see any significant correlation between leaf rolling and apoplastic antioxidants (Table 3).

\section{Antioxidants of residual leaf and petiole}

Glutathione content in residual leaf was higher than that of the petiole. GSH content was enhanced as the drought period progressed, indicating a relationship between glutathione accumulation and GR activity. The level of GSH increased by 99 $\%, 195 \%$ and $153 \%$ at score 2, 3 and 4 in leaf. However, in the petiole, it decreased by $20 \%$ at score 2 , but increased by $46 \%$ and $48 \%$ at score 3 and 4 compared to score 1 , respectively. Drought caused a significant decrease in GSSG in the leaf. In contrast, GSSG increased at score 2, then did not change at score 3 and 4 in the petiole (Table 2). Moreover, a significant negative correlation between leaf rolling and GSSG content ( $\mathrm{r}=-0.93$ ) was observed during the rolling period (Table 3 ).

ASC content increased at score 2 and 3 , but declined at score 4 in the leaf. The content of ASC increased in the petiole at score 2 , but decreased at score 3 and 4 . It was found that symplastic DHA enhanced

TABLE 1

The changes in ASC and DHA content during leaf rolling in C. setosa.

ASC and DHA contents were expressed as $\mu \mathrm{g} \mathrm{g}^{-1}$ fresh weight.

\begin{tabular}{|c|c|c|c|c|c|c|c|c|}
\hline \multirow{3}{*}{$\begin{array}{l}\text { Visual le } \\
\text { rolling } \\
\text { scores }\end{array}$} & \multicolumn{4}{|c|}{ Apoplast } & \multicolumn{4}{|c|}{ Symplast } \\
\hline & \multicolumn{2}{|c|}{$\mathrm{ASC}$} & \multicolumn{2}{|c|}{ DHA } & \multicolumn{2}{|c|}{$\mathrm{ASC}$} & \multicolumn{2}{|c|}{ DHA } \\
\hline & Leaf & Petiole & Leaf & Petiole & Leaf & Petiole & Leaf & Petiole \\
\hline 1 & $0.9 \pm 0.02 \mathrm{a}^{*}$ & $0.4 \pm 0.01 \mathrm{a}$ & $2.8 \pm 0.07 \mathrm{a}$ & $1.8 \pm 0.03 \mathrm{c}$ & $51.1 \pm 0.8 b$ & $3.5 \pm 0.6 \mathrm{c}$ & $125 \pm 1.3 \mathrm{a}$ & $31 \pm 1.6 \mathrm{c}$ \\
\hline 2 & $1.5 \pm 0.02 \mathrm{~d}$ & $0.6 \pm 0.02 c$ & $7.4 \pm 0.04 \mathrm{c}$ & $1.21 \pm 0.1 \mathrm{a}$ & $67.5 \pm 1.6 \mathrm{c}$ & $6.8 \pm 0.05 \mathrm{~d}$ & $273.2 \pm 6.8 \mathrm{c}$ & $36 \pm 2.7 d$ \\
\hline 3 & $1.4 \pm 0.02 \mathrm{c}$ & $0.5 \pm 0.04 b$ & $6.8 \pm 0.08 b$ & $1.6 \pm 0.03 b$ & $64.0 \pm 1.3 \mathrm{c}$ & $1.5 \pm 0.02 b$ & $267 \pm 1.5 c$ & $26 \pm 0.1 b$ \\
\hline 4 & $1.2 \pm 0.08 b$ & $0.7 \pm 0.1 \mathrm{c}$ & $6.9 \pm 0.1 \mathrm{~b}$ & $1.3 \pm 0.02 \mathrm{a}$ & $48.1 \pm 1.1 \mathrm{a}$ & $0.5 \pm 0.07 \mathrm{a}$ & $260 \pm 1.2 b$ & $22 \pm 0.1 \mathrm{a}$ \\
\hline
\end{tabular}

* Different letters in each column denote significant differences among means. Mean comparison among leaf rolling scores was performed using the ANOVA test at $\mathrm{p} \leq 0.05$. Mean values \pm standard deviation of six replicates.

TABLE 2

The changes in GSH and GSSG content during leaf rolling in C. setosa. GSH and GSSG contents were expressed as nmol g-1 fresh weight.

\begin{tabular}{lcccr}
\hline Visual leaf rolling scores & \multicolumn{2}{c}{ Leaf } & \multicolumn{2}{c}{ Petiole } \\
\cline { 2 - 3 } & GSH & GSSG & GSH & GSSG \\
\hline 1 & $185 \pm 12 \mathrm{a}^{*}$ & $87 \pm 1.7 \mathrm{c}$ & $54 \pm 0.9 \mathrm{~b}$ & $15 \pm 1.1 \mathrm{a}$ \\
2 & $369 \pm 17 \mathrm{~b}$ & $56 \pm 0.5 \mathrm{~b}$ & $43 \pm 0.8 \mathrm{a}$ & $26 \pm 1.8 \mathrm{~b}$ \\
3 & $546 \pm 17 \mathrm{~d}$ & $53 \pm 3.6 \mathrm{~b}$ & $79 \pm 1.7 \mathrm{c}$ & $13 \pm 3.5 \mathrm{a}$ \\
4 & $468 \pm 24 \mathrm{c}$ & $39 \pm 1.2 \mathrm{a}$ & $80 \pm 3.5 \mathrm{c}$ & $12 \pm 2.5 \mathrm{a}$ \\
\hline
\end{tabular}

* Different letters in each column denote significant differences among means. Mean comparison among leaf rolling scores was performed using the ANOVA test at $p \leq 0.05$. Mean values \pm standard deviation of six replicates. 
during rolling in the leaf. The content of DHA in the petiole significantly enhanced at score 2, but decreased at score 3 and 4 (Table 1). There were no good correlations between leaf rolling and ASC and DHA (Table 3).

\section{DISCUSSION}

In the previous study, it was recorded that leaf water potential and RWC decreased during leaf rolling. Moreover, the decrease in RWC of the petiole was higher than that of the leaf during the rolling period. For example, RWCs of the leaf and petiole were $95 \%$ and $97 \%$ at score 1 , but $78 \%$ and 68 $\%$ at score 4 , respectively. Water potentials of leaves were reduced $-0.15 \mathrm{MPa}$ at score 1 to $-1.18 \mathrm{MPa}$ at score 4 (data not shown). In the present study, the role of the antioxidant defense system, and more specially, the role of enzymes of the ASC-GSH cycle have been examined during leaf rolling under drought stress. Significant differences have been determined in ASC-GSH cycle related enzyme activities (APX, GR, MDHAR and DHAR) and antioxidant (ASC and GSH) contents between apoplastic and symplastic fractions.

G6PDH was used as a cytoplasmic marker enzyme to determine the degree of contamination of the apoplastic extracts by components originating from within the cells. G6PDH activity in AWF was below the limits of detection $(1 \%)$ in $C$. setosa. Similarly, the activity of G6PDH in the apoplast of barley leaves was below $1 \%$ (Padu et al. 1999).

APX, MDHAR, DHAR, and GR are considered to constitute the Asada-Halliwell pathway enzymes for the scavenging of active oxygen species. Scavenging of $\mathrm{H}_{2} \mathrm{O}_{2}$ by APX is the first step of the ASC-GSH cycle. DHAR, MDHAR and GR also participate in this cycle (Foyer and Halliwell, 1976; Asada, 1994). In our previous study, apoplastic APX activity in the leaf and petiole of Ctenanthe increased, but did not change in the symplastic areas of leaf (data not shown). In the study, it was reported that an increase in apoplastic APX activity may result from the high increase of $\mathrm{H}_{2} \mathrm{O}_{2}$ content in the same area.

In the present study, the activities of symplastic DHAR and MDHAR from others of the Asada-Halliwell pathway enzymes significantly increased during leaf rolling (Fig. 3, 4). These results are consistent with the findings of Selote and Chopra (2006), who reported that DHAR and MDHAR activities increased significantly in wheat seedlings during mild and severe water stress. Increase in symplastic DHAR activity may be related to an increase in DHA level in the leaf. Thus, it causes that more ASC is produced from DHA. Also, under drought stress, a significant increase of DHAR and

Linear correlations among leaf rolling and ASC-GSH cycle enzymes (DHAR, MDHAR and GR), and antioxidant substances (ASC, DHA, GSH and GSSG). The correlation coefficient (r) and significant differences are given.

\begin{tabular}{lccccccccc}
\hline & \multicolumn{3}{c}{ Leaf } & & \multicolumn{4}{c}{ Petiole } \\
\cline { 1 - 3 } \cline { 7 - 9 } Apoplast & Leaf Rolling & Simplast & Leaf Rolling & & Apoplast & Leaf Rolling & Simplast & Leaf Rolling \\
\hline GR & $0.92^{* *}$ & GR & $0.91^{* *}$ & & GR & 0.22 & GR & -0.42 \\
ASC & 0.39 & DHAR & $0.96^{* *}$ & & ASC & 0.80 & DHAR & 0.26 \\
DHA & 0.70 & MDHAR & 0.69 & & DHA & -0.52 & MDHAR & 0.16 \\
& & ASC & -0.16 & & & & ASC & -0.66 \\
& & DHA & 0.72 & & & & DHA & -0.78 \\
& & GSH & 0.84 & & & & GSH & 0.79 \\
& & GSSG & $-0.93^{* *}$ & & & & GSSG & -0.44 \\
\hline
\end{tabular}


MDHAR activities in the petiole can be explained with a significant increase in GSH concentration. However, DHAR and MDHAR activities were not found in the apoplast of Ctenanthe, as was obtained in the similar Plantago major (Lyons et al., 1999), Fagus sylvatica (Luwe, 1996), Picea abies (Polle et al., 1990) and Sedum album (Castillo and Greppin 1988) leaves. As with Foyer and Halliwell (1976), it was concluded that considerable regeneration of ASC from DHA by the ASC-GSH pathway may not take place in the apoplast of $C$. setosa because no DHAR activity was observed in the apoplast.

In our experiments, it was also found that symplastic GR activity increased during leaf rolling under drought in the leaf (Fig. 2B). GR plays a very important role in maintaining high ratio of $\mathrm{NADPH} / \mathrm{NADP}^{+}$ in the cell and a crucial role in the generation of GSH from GSSG (Jain, 1998). It was thought that GR activity enhanced in the leaf because GSH concentration increased in this organ. Similarly Sharma and Dubey (2005) have reported an increase in GR activity in rice originated from enhanced GSH level. Contrary to GR activity in the leaf, the results showed that symplastic GR activity decreased in the petiole (Fig. 2B). This result can be explained by the fact that the GSSG level does not change in the petiole.

In the current study, apoplastic GR activity increased in leaves during leaf rolling. In the petiole, however, it increased up to score 3 , but then declined to the level of score 1 (Fig. 2A). According to these results, we can conclude that GR has a function to scavenge ROS accumulated in the apoplastic areas by ASC-GSH cycle. Similarly, it has been pointed out that increases in GR activity in response to elevated oxygen concentrations suggest a prominent role for this enzyme in the protection of leaf tissue against oxidative damage (Foster and Hess, 1982; Gamble and Burke, 1984).

Our results show that symplastic ASC content increased up to score 3 , but then decreased as compared to score 1 in the leaf (Table 1). Decrease of symplastic ASC content may be explained by its oxidation to DHA by ROS. Similar to our results, it was determined that DHA content enhanced, while ASC content decreased in rice under water stress (Boo and Jung, 1999; Boo et al., 2000). ASC in the symplast of petiole also increased at the beginning of leaf rolling, but then decreased (Table 1). Decrease of ASC content in petiole could be explained as APX is using ASC as a substrate.

In this work, the ASC content of the apoplast increased compared to score 1 in the leaf and petiole during leaf rolling, but DHA content increased in leaf while it decreased in the petiole (Table 1). Ascorbate may be transported across the plasma membrane in the petiole of $C$. setosa. Indeed, decrease in ASC content of symplastic area of the petiole shows that symplastic ASC may be transported from the cytosol to apoplast in the plant during leaf rolling. In the leaf, production of symplastic ASC was higher than that of petiole. Thus, it can be said that ASC production also goes on while ASC is transported to the apoplastic area.

In this study, neither GSH nor GSSG were present in the apoplast of C. setosa. Similarly some works have detected very little or no GSH in the apoplast (Luwe, 1996; Vanacker et al., 1998; Lyons et al., 1999). Since GSH is not placed in apoplast of $C$. setosa, regeneration of ASC from DHA via the ASC-GSH cycle (Foyer and Halliwell, 1976) may not occur in the apoplast. In the current study, symplastic GSH content during rolling also increased in the leaf and petiole, similar to rice under drought stress (Sharma and Dubey, 2005). The increase in GSH content in the leaf may originate from enhanced $\mathrm{H}_{2} \mathrm{O}_{2}$ and GR activity. Similar to results on GR activity, it was suggested that $\mathrm{H}_{2} \mathrm{O}_{2}$ level increased during leaf rolling in $C$. setosa (data not shown). It was shown that the increase in $\mathrm{H}_{2} \mathrm{O}_{2}$ level enhanced the antioxidant substances and antioxidative enzymes in some plants (Creissen et al., 1996; Lechno et al., 1997). Furthermore, it is thought that an increase in the GSH level is necessary for regulation of ASC and DHA levels. While symplastic GSH contents increased, GSSG content significantly decreased in the 
leaf of C. setosa (Table 2). These results show that GR uses NADPH as a substrate and so generates GSH from GSSG. It is known that GR uses NADPH to reduce GSSG to GSH and so it can play a role in maintaining the high ratio of NADPH/ $\mathrm{NADP}^{+}$in the cell (Creissen et al., 1996). In contrast to the leaf, where GSH content was decreasing, GSSG increased in the petiole at score 2 compared to score 1 (Table 2). GSSG accumulation may have resulted from the decrease of GR activity in the symplastic area of petiole. Also, while GSH increased at scores 3 and 4, GSSG did not change compared to score 1 . Moreover, GR activity declined in the petiole. The increase in GSH content may have originated from non-enzymatic reactions.

The results show that ASC-GSH cycle enzymes were induced in a different manner by ROS in the leaf and petiole. For this reason, the antioxidant levels (GSH and ASC) and the activities of antioxidant enzymes in the petiole were not higher than those of the leaf, although the decrease in RWC of the petiole was higher than that of the leaf during the rolling period. This difference may originate from different structures or the rolling behavior of two plant parts.

In conclusion, ASC-GSH cycle enzymes may have a role in controlling leaf rolling to scavenge ROS in the apoplastic and symplastic areas of leaf and petiole in $C$. setosa. Moreover, leaf rolling provides a protection not only for the leaf, but also for the petiole by decreasing water loss through leaf surfaces.

\section{ACKNOWLEDGEMENT}

This work is supported by Turkish National Science Foundation (COST FA 0605 Action) Project No: 105T354. We thank to Prof. Dr. Faik Ahmet Ayaz for analysis of HPLC measurements.

\section{REFERENCES}

ARORA A, SAIRAM RK, SRIVASTAVA GC (2002) Oxidative stress and antioxidative system in plants. Curr Sci 82: 1227-1238
ASADA K (1994) Production and action of active oxygen species in photosynthetic tissues. In: FOYER $\mathrm{CH}$, MULLINEAUX PM (eds) Causes of Photooxidative Stress and Amelioration of Defense Systems in Plants. Boca Raton: CRC Press, FL, pp: 77-104

ASADA K (1999) The water-water cycle in chloroplasts: scavenging of active oxygen and dissipation of excess photons. Annu Rev Plant Physiol Plant Mol Biol 50: 601-639

BEGG JE (1980) Morphological adaptation of leaves to water stress. In: TURNER NC, KRAMER PJ (eds) Adaptation of Plants to Water and High Temperature Stress. New York: Wiley Interscience, pp: 33-42

BOO YC, JUNG J (1999) Water deficit induced oxidative stress and antioxidative defences in rice plants. J Plant Physiol 155: 255-261

BOO YC, LEE KP, JUNG J (2000) Rice plants with a high protochlorophyllide accumulation show oxidative stress in low light that mimics water stress. J Plant Physiol 157: 405-411

CASTILLO FJ, GREPPIN H (1988) Extracellular ascorbic acid and enzyme activities related to ascorbic acid metabolism in Sedum album L. leaves after ozone exposure. Environ Exp Bot 28: 231-238

CASTILLO FJ (1996) Antioxidative protection in the inducible CAM plant Sedum album L. following the imposition of severe water stress and recovery. Oecologia 107: 469-477

CLARKE JM (1986) Effect of leaf rolling on leaf water loss in Triticum spp. Can J Plant Sci 66: 885-891

CREISSEN $G$, BROADBENT P, STEVENS $R$, WELLBURN AR, MULLINEAUX PM (1996) Manipulation of glutathione metabolism in transgenic plants. J Biochem 24: 465-472

DALTON DA (1995) Antioxidant defences of plants and fungi. In: AHMAD S (ed) Oxidative Stress and Antioxidant Defences in Biology. New York: Chapman Hall, pp: 298-355

DE CABO RC, GONZALES-REYES JA, CORDOLA F, NAVAS P (1996) Rooting hastened in onions by ascorbate and ascorbate free radical. J Plant Growth Regul 15: 53-56

del RIO LA, CORPAS FJ, SANDALIO LM, PALMA JM, GOMEZ M, BARROSO JB (2002) Reactive oxygen species, antioxidant systems and nitric oxide in peroxisomes. J Exp Bot 53: 1255-1271

DIETZ KJ (1997) Functions and responses of the leaf apoplast under stress. Prog Bot 58: 221-254

FOSTER JG, HESS JL (1982) Oxygen effects on maize leaf superoxide dismutase and glutathione reductase. Phytochemistry 21: 1527-1532

FOYER CH, HALLIWELL B (1976) Presence of glutathione and glutathione reductase in chloroplast: a proposed role in ascorbic acid metabolism. Planta 133: 21-25

FOYER CH (1993) Ascorbic acid. In: ALSCHER RG, HESS JL (eds) Antioxidants in Higher Plants. Boca Raton: CRC Press, pp: 31-58

GAMBLE PE, BURKE JJ (1984) Effect of water stress on the chloroplast antioxidant system, I. alterations in glutathione reductase activity. Plant Physiol 76: 615621

GRIFFITH OW (1980) Determination of glutathione and glutathione disulphide using glutathione reductase and 2-vinylpyridine. Anal Biochem 106: 207-212

HERNANDEZ JA, FERRER MA, JIMENEZ A, BARCELO AR, SEVILLA F (2001) Antioxidant system and $\mathrm{O}_{2}-1$ $\mathrm{H}_{2} \mathrm{O}_{2}$ production in the apoplast of pea leaves. Its relation with salt-induced necrotic lesions in minor veins. Plant Physiol 127: 817-831 
HOSSAIN MA, ASADA K (1984) Purification of dehydroascorbate reductase from spinach and its characterization as a thiol enzyme. Plant Cell Physiol 25: 85-92

HOSSAIN MA, NAKANO Y, ASADA K (1984) Monodehydroascorbate reductase in spinach chloroplasts and its participation in regeneration of ascorbate for scavenging hydrogen peroxide. Plant Cell Physiol 25: 385-395

HU JF, LI GF, GAO ZH, CHEN L, REN HB, JIA WS (2005) Regulation of water deficit-induced abscisic acid accumulation by apoplastic ascorbic acid in maize seedlings. J Integr Plant Biol 47: 1335-1344

KADIOGLU A, TERZI R (2007) A dehydration avoidance mechanism: leaf rolling. Bot Rev 73: 290-302

KORNBERG A, HORECKER BL (1955) Glucose-6Phosphate dehydrogenase. In: COLOWICK SP, KAPLAN NO (eds) Methods in Enzymology. New York: Academic Press, NY, USA, pp: 363-368

JAIN SK (1998) Glutathione and glucose-6-phosphate dehydrogenase deficiency can increase protein glycosylation. Free Radical Bio Med 24: 197-201

JASPERS P, KOLLIST H, LANGEBARTELS C, KANGASJÄRVI J (2005) Plant responses to ozone. In: SMIRNOFF N (ed) Antioxidants and reactive oxygen species in plants. Oxford: Blackwell Publishing, pp: 268-292

LECHNO SE, TEL-OR E (1997) Salt stress-induced responses in cucumber plants. J Plant Physiol 150: 206-210

LI L, STADEN JV (1998) Effects of plant growth regulators on the antioxidant system in callus of two maize cultivars subjected to water stress. Plant Growth Regul 24: 55-66

LYONS T, OLLERENSHAW JH, BARNES JD (1999) Impacts of ozone on Plantago major: apoplastic and symplastic antioxidant status. New Phytol 141: 253 263

LYONS TM, PLOCHL M, TURCSANYI E, BARNES JD (2001) Extracellular antioxidants: a protective screen against ozone. In: AGRAWAL SB, AGRAWAL M (eds) Environmental Pollution and Plant Responses. London: UK, Lewis Publisher, pp: 183-194

LUWE M (1996) Antioxidants in the apoplast and symplast of beech (Fagus sylvatica L.) leaves: seasonal variations and responses to changing ozone concentrations in air. Plant Cell Environ 19: 321-328
MEHLHORN H, LELANDAIS M, KORTH HG, FOYER $\mathrm{CH}$ (1996) Comparision of ascorbate-dependent peroxidase activity in horseradish peroxidase types I and II and in leaf extracts. FEBS Lett 378: 203-206

MÖLLER IM (2001) Plant mitochondria and oxidative stress: electron transport, NADPH turnover, and metabolism of reactive oxygen species. Annu Rev Plant Physiol Plant Mol Biol 52: 561-591

O'TOOLE JC, MOYA TB (1978) Genotypic variation in maintenance of leaf water potential in rice. Crop Sci 18: $873-876$

PADU E, MOLDAU H, KOLLIST H (1999) The effect of ozone an antioxidative reactions in apoplast and symplast of barley leaves. Plant Peroxidase Newslett $133-138$

POLLE A, CHAKRABARTI K, SCHURMANN W, RENNENBERG H (1990) Composition and properties of hydrogen peroxide decomposing systems in extracellular and total extracts from needles of Norway spruce (Picea abies L., Karst.). Plant Physiol 94: 312319

SELOTE DS, CHOPRA RK (2006) Drought acclimation confers oxidative stress tolerance by inducing coordinated antioxidant defense at cellular and subcellular level in leaves of wheat seedlings. Physiol Plantarum 127: 494-506

SHARMA P, DUBEY RS (2005) Drought induced oxidative stress and enhances the activities of antioxidant enzymes in growing rice seedlings. Plant Growth Regul 46: 209-221

SMIRNOFF N, PALLANCA JE (1996) Ascorbate metabolism in relation to oxidative stress. Biochem Soc T 24: 472-478

TAKAHAMA U, ONIKI T (1992) Regulation of peroxidase-dependant oxidation of phenolics in the apoplast of spinach leaves by ascorbate. Plant Cell Physiol 33: 379-387

TOWNLEY-SMITH TF, HURD EA (1979) Testing and selecting for drought resistance in wheat. In: MUSSELL H, STAPLES RC (eds) Stress Physiology in Crop Plants. John New York: Wiley and Sons, pp: 447-464

TURGUT R, KADIOĞLU A (1998) The effect of drought, temperature and irradiation on leaf rolling in Ctenanthe setosa. Biol Plantarum 41: 629-663

VANACKER H, HARBINSON J, RUISCH J, CARVER TLW, FOYER CH (1998) Antioxidant defences of the apoplast. Protoplasma 205: 129-140. 